\title{
Extended Scale for the Hydrogen-Bond Basicity of Ionic Liquids
}

\author{
Ana Filipa M. Cláudio, ${ }^{a}$ Lorna Crowhurst, ${ }^{b}$ Jason P. Hallett, ${ }^{b}$ Tom Welton, ${ }^{b}$ João A. P. Coutinho ${ }^{a}$ and \\ Mara G. Freire* ${ }^{* a}$
}

Received (in $X X X, X X X)$ Xth $X X X X X X X X X 20 X X$, Accepted Xth $X X X X X X X X X 20 X X$

${ }_{5}$ DOI: 10.1039/b000000x

In the past decade, ionic liquids (ILs) have been the focus of intensive research regarding their use as potential and alternative solvents in many chemical applications. Targeting their effectiveness, recent investigations have attempted to establish polarity scales capable of ranking ILs according to their chemical behaviours. However, some major drawbacks have been found since polarity scales are only

10 report relative behaviours because they depend on the set of probe dyes used, and they are sensitive to measurement conditions such as purity levels of the ILs and procedures employed.. Due to all these difficulties it is of crucial importance to find alternative and/or predictive methods and to evaluate them as a priori approaches able to provide the chemical properties of ILs. Furthermore, the large number of ILs available makes their experimental characterization, usually achieved by a trial and error

15 methodology, burdensome. In this context, we firstly evaluated COSMO-RS, Conductor-Like Screening Model for Real Solvents, as an alternative tool to estimate the hydrogen-bond basicity of ILs. After demonstrating a straight-linecorrelation between the experimental hydrogen-bond basicity values and the COSMO-RS hydrogen-bonding energies in equimolar cation-anion pairs, an extended scale for the hydrogen-bond accepting ability of IL anions is proposed here. This new ranking of the ILs chemical

${ }_{20}$ properties opens the possibility to pre-screen appropriate ILs (even those not yet synthesized) for a given task or application.

\section{Introduction}

In the past few years, ionic liquids (ILs) have been proposed as promising liquids for the substitution of volatile organic solvents ${ }_{25}$ widely used in industry. ${ }^{1}$ ILs are typically composed of large and asymmetric organic cations and organic or inorganic anions. Due to their large ions, and thus delocalization of charge, ILs display lower melting temperatures in comparison toconventional salts salts with melting temperatures below $100{ }^{\circ} \mathrm{C}$ are generally 30 recognised to be ILs. Their ionic nature also confers singular characteristics to most ILs, namely a negligible vapour pressure and low flammability at ambient conditions. In fact, these are the main features for their being widely described as "green solvents" and for much of the interest in these as potential solvents for 35 "clean" technologies. Nevertheless, it should be remarked that other properties, such as their toxicity and biodegradability, ${ }^{2}$ should be investigated before such generalized assumptions can be confirmed. However, it is generally accepted that the use of non-volatile liquid solvents at ambient conditions is already a 40 major contribution to reduce the environmental human footprint.

In addition to the previously described characteristics, ILs are salts with a high solvation ability and selectivity. ${ }^{3}$ In particular, the possibility to tune their properties, thereby creating "tailor made" compounds through the modification of their chemical 45 structures, has led to the synthesis of ILs with a wide variety of applications. ILs (as alternative solvents) have been largely used in catalysis and in a large assortment of organic/inorganic/organometallic reactions ${ }^{4}$, in the treatment and/or dissolution of biomass 5 and in liquid-liquid extractions and 50 separations ${ }^{6}$. Nevertheless, an efficient and realistic use of ILs as solvents requires the previous knowledge of their physical and chemical properties. The main challenge consists therefore in the development of a "tailored solvent" for a target application. For that purpose, it is crucial to understand the solvation interactions 55 at a molecular level in order to further evaluate the performance of a given solvent. Among the most important features of an IL to be used as a solvent are the specific interactions occurring between the solvent and the dissolved substrate (solute-solvent interactions) which are usually related to the solvent polarity. It ${ }_{60}$ has previously been demonstrated that the IL polarity influences its solvation ability, reaction rates, reaction mechanisms,product yields and enzyme activity, among others. ${ }^{7}$

One of the methods most often employed to estimate the polarity of ILs is the analysis of the UV-Vis spectral band shifts 65 of solvatochromic probes. Specific and nonspecific solute-solvent interactions are reflected in the respective absorbances of a suite of selected dyes. ${ }^{8-9}$ A number of empirical solvatochromic parameters has been suggested to quantify the molecularmicroscopic solvent properties of ILs. $^{8-9}$ For the sake of 70 simplicity only one indicator is frequently used to build the polarity scale and, amongst the various possibilities, the $\mathrm{E}_{\mathrm{T}}(30)$ Reichardt's betaine dye has been widely employed. ${ }^{8} \mathrm{E}_{\mathrm{T}}(30)$ is a measure of the solvent dipolarity/polarizability, though it is also sensitive to the solvents' hydrogen-bond donor ability. On the 
other hand, a multiparametric approach was proposed by Kamlet, Taft and co-workers ${ }^{9}$ and consists in the use of a set of solvatochromic probes which allow the assessment of different parameters for the same solvent.

5 The Kamlet-Taft equation ${ }^{9}$, in its simple form of a Linear Solvation Energy Relationship (LSER), is given by the following equation,

$$
X Y Z=(X Y Z)_{0}+s\left(\pi^{*}+\mathrm{d} \delta\right)+a \alpha+b \beta
$$

where $X Y Z$ is the result of a particular solvent-dependent process, $(X Y Z)_{0}$ is the value for the reference system, $\pi^{*}$ represents the solvent's dipolarity/polarizability, $\alpha$ is the hydrogen-bond donating ability, $\beta$ is the hydrogen-bond accepting ability and $\delta$ is 15 a correction term. The parameters $a, b$ and $s$ represent the solvent-independent coefficients. ${ }^{9}$

Different dyes and experimental approaches can result in diverse values of solvatochromic parameters for the same solvent. ${ }^{8-9}$ In this context, different empirical techniques only 20 provide uniquely defined scales of relative polarity. For instance, two structurally similar probes, $N, N$-diethyl-3-nitroaniline and $N, N$-diethyl-4-nitroaniline, lead to different values of $\pi^{*}$ for the same IL. ${ }^{10}$ This trend is a result of the diverse and complex interactions that occur between the solvent and a particular solute, 25 i.e., the polarity scales are always solute-dependent. Published data for $\alpha, \beta$ and $\pi^{*}$ for specific ILs are quite different and mainly depend on the set of solvatochromic dyes employed. ${ }^{10-11}$

The Kamlet-Taft parameters are well established for traditional solvents and it is one of the most accepted (used) polarity ${ }_{30}$ scales. ${ }^{12}$ Nevertheless, for more recent solvents such as ILs, these parameters are still not definitive and are undergoing continuous experimental measurements by several research groups. ${ }^{10-11}$ One of the major reasons behind this is the sensitivity of the KamletTaft values to impurities. ${ }^{10,13}$ In ILs, many of these impurities 35 come from their own synthesis. Improvements on the synthetic routes of ILs are also under constant development. ${ }^{14}$ Recently, it was demonstrated that water, 1-methylimidazole, 1-chlorobutane and the ions of the salts precursors significantly influence the values of the solvatochromic parameters of ILs. ${ }^{10,15}$ One of the 40 major advantages of ILs over the traditional solvents is their lack of vapour pressure at ambient conditions. However, this low volatility doesn't allow their purification by simple distillation. Only volatile impurities can thus be removed by heating under vacuum. Furthermore, to simplify the experimental tasks, ILs 45 should ideally be liquid at room temperature and non-coloured. Finally, the Kamlet-Taft parameters are obtained as average values of a series of selected probes requiring thus require a considerable experimental effort to derive the respective parameters for any new solvent. Still, and despite some 50 divergences found between different authors and probe dyes, it is generally accepted that: $(i)$ the dipolarity/polarizability $\left(\pi^{*}\right)$ values are similar amongst several ILs and are higher than those of most molecular solvents (Coulombic interactions as well as dipole and polarizability effects occur in ILs); (ii) the hydrogen55 bond basicity values cover a large range, from similar to acetonitrile to lower values, and are mainly controlled by the IL anion; and (iii) the hydrogen-bond acidity values of ILs are comparable to or lower than that of aniline and are mainly determined by the IL cation (although the anion also plays a 60 secondary role since stronger cation-anion interactions further reduce the ability of the cation to interact with the substrate). ${ }^{10-11}$

Aiming at overcoming the difficulties encountered with common solvatochromic probes and the establishment of polarity scales in ILs, several attempts have been carried out in order to ${ }_{65}$ find suitable alternatives. For instance, Chiappe and Pieraccini ${ }^{16}$ studied the formation of an electron donor-acceptor complex between 4,4'-bis(dimethylamino)benzophenone and tetracyanoethene and correlated its visible absorption maximum with the Kamlet-Taft parameters. $\mathrm{Wu}$ et al. ${ }^{17}$ proposed a 70 spectroscopic method based on the transition energy of spiropyran probes and demonstrated its correlation with the polarity of ILs by means of the $\mathrm{E}_{\mathrm{T}}(30)$ values. Lungwitz and coworkers ${ }^{18}$ established that there is a close correlation between $\alpha$ and $\beta$. The same research group ${ }^{18}$ proved that $\beta$ also correlates 75 with the ${ }^{1} \mathrm{H}$ NMR chemical shift of the most acidic proton of the imidazolium cation. More recently, Hunt and co-workers ${ }^{19}$ proposed the use of different computational descriptors for predicting Kamlet-Taft parameters, namely $\alpha$ and $\beta$, in ILs.

Due to all the difficulties found hitherto to establish a polarity 80 scale for ILs, it is of crucial importance to find alternative and/or predictive methods. Furthermore, the large number of ILs available from their structural flexibility also represents a major drawback in that it is unfeasible to experimentally determine the solvatochromic parameters for all the cation/anion combinations

85 which may form an IL. Therefore, we provide here novel results on the use of COSMO-RS, Conductor-Like Screening Model for Real Solvents, ${ }^{20}$ as a valuable tool to estimate the hydrogen-bond basicity, $\beta$, of ILs. COSMO-RS is based on unimolecular quantum calculations and is mostly used for the prediction of ${ }_{90}$ phase equilibrium. ${ }^{21}$ COSMO-RS is also valuable in the prediction of the excess properties of binary mixtures composed of molecular solvents and ILs, as well as between ILs and gases or other volatile compounds. ${ }^{22}$

\section{Results and discussion}

\section{${ }_{95}$ Experimental Kamlet-Taft solvatochromic parameters}

There are two major literature sources reporting the KamletTaft parameters for 1-butyl-3-methylimidazolium-([ $\left.\left.\mathrm{C}_{4} \mathrm{mim}\right]\right)$ based ILs with the main goal of appraising the effect of the IL anion through its hydrogen-bond basicity. ${ }^{10,18}$ To expand this 100 database, additional Kamlet-Taft solvatochromic parameters were here determined for $4 \mathrm{ILs}$ based on the $\left[\mathrm{C}_{4} \mathrm{mim}\right]^{+}$cation. A list of the studied fluids, including a definition of their acronyms, is provided as an endnote. ${ }^{\star}$ There are several sets of dyes that can be used to determine the Kamlet-Taft parameters. In this work, 105 the Reichardt's dye, 4-nitroaniline and $N, N$-diethyl-4-nitroaniline were used. All spectra were recorded at $25^{\circ} \mathrm{C}$, and thus, only ILs that are liquid at room temperature were appraised. The values of the Kamlet-Taft solvatochromic parameters determined in this work are reported in Table 1.

110 The solvatochromic data for $\left[\mathrm{C}_{4} \mathrm{mim}\right]\left[\mathrm{CF}_{3} \mathrm{SO}_{3}\right]$ and $\left[\mathrm{C}_{4} \mathrm{mim}\right]\left[\left(\mathrm{CH}_{3} \mathrm{O}\right)_{2} \mathrm{PO}_{2}\right]$ are in close agreement with previous published data ${ }^{10,19}$ whereas novel results are presented for the $\left[\mathrm{C}_{4} \mathrm{mim}\right]\left[\mathrm{C}_{8} \mathrm{H}_{17} \mathrm{SO}_{4}\right]$ and $\left[\mathrm{C}_{4} \mathrm{mim}\right]\left[\mathrm{CF}_{3} \mathrm{CO}_{2}\right]$.

The $\pi^{*}$ values are high for all the ILs investigated in 
comparison to non-aqueous molecular solvents ${ }^{9}$ and slightly depend on the IL anion. $\pi^{*}$ is a true measure of the ion-dye nonspecific interactions (polarizability, and dipole-dipole and dipoleinduced dipole interactions) and tends to decrease with the 5 increase on the charge delocalization of the IL anion. ${ }^{10}$ In fact, the octylsulphate-based IL is the one which presents the lowest $\pi^{*}$ value - a consequence of the long aliphatic moiety present in this anion.

Table 1. Kamlet-Taft parameters using the following set of dyes: ${ }_{10}$ Reichardt's Dye, $N, N$-diethyl-4-nitroaniline and 4-nitroaniline.

\begin{tabular}{cccc}
\hline $\mathrm{IL}$ & $\alpha$ & $\beta$ & $\pi^{*}$ \\
\hline$\left[\mathrm{C}_{4} \mathrm{mim}\right]\left[\mathrm{CF}_{3} \mathrm{SO}_{3}\right]$ & 0.62 & 0.48 & 0.98 \\
{$\left[\mathrm{C}_{4} \mathrm{mim}\right]\left[\mathrm{C}_{8} \mathrm{H}_{17} \mathrm{SO}_{4}\right]$} & 0.65 & 0.80 & 0.93 \\
{$\left[\mathrm{C}_{4} \mathrm{mim}\right]\left[\left(\mathrm{CH}_{3} \mathrm{O}\right)_{2} \mathrm{PO}_{2}\right]$} & 0.48 & 1.12 & 0.96 \\
{$\left[\mathrm{C}_{4} \mathrm{mim}\right]\left[\mathrm{CF}_{3} \mathrm{CO}_{2}\right]$} & 0.57 & 0.84 & 0.94 \\
\hline
\end{tabular}

As previously demonstrated in the literature, the hydrogenbond acidity of ILs is mainly determined by the IL cation; ${ }^{10}$ yet, there is also a clear dependence on the IL anion, as shown here 15 and in agreement with literature data. ${ }^{10}$ The data presented in Table 1 reveal that the ability of the IL to act as a hydrogen-bond donor (mainly arising fromthe IL cation) is moderated by the hydrogen-bond acceptor ability of the anion composing the respective IL. For instance, the dimethylphosphate-based IL, 20 having an anion with the highest ability to accept a hydrogen bond, is the one with the lowest $\alpha$ value. The high ability of this anion to hydrogen-bond with the IL cation limits its availability to interact as a hydrogen bond donor to the dye.

The $\beta$ value reflects the hydrogen-bond basicity of each IL 25 acting as a solvent. As shown in Table 1 , the $\beta$ values are strongly dependent on the IL anion. Between the studied ILs, the dimethylphosphate-based fluid presents the highest ability to hydrogen-bond with the protons of the hydrogen bond donor group $\left(-\mathrm{NH}_{2}\right)$ of the 4-nitroaniline dye.

\section{${ }_{30}$ Estimation of the hydrogen-bond basicity of ILs}

Taking into account all the difficulties in experimentally determining the Kamlet-Taft solvatochromic parameters we tested the COSMO-RS as a viable and expeditious tool to estimate the hydrogen-bond basicity of $\left[\mathrm{C}_{4} \mathrm{mim}\right]$-based ILs. The 35 hydrogen-bond basicity was chosen in this work since it is one of the most important parameters reflecting the hydrogen-bond acceptor ability of the IL anion. Most of the relevant properties of ILs regarding this solute-solvent interaction are significantly determined by the nature of the anion rather than the cation. ${ }^{23}$ In 40 fact, the $\beta$ parameter is widely used to explain (and indeed correlates with) diverse properties, such as solvation ability and phase equilibrium behaviour of ILs. ${ }^{24}$ Within this perspective, the hydrogen-bond basicity was here correlated with the hydrogenbonding interaction energy in the equimolar cation-anion mixture ${ }_{45}\left(E_{\mathrm{HB}} /\left(\mathrm{kJ} \cdot \mathrm{mol}^{-1}\right)\right)$ obtained from COSMO-RS to infer a possible dependence. It should be remarked that other attempts were also carried out, namely the correlation of the hydrogen-bond basicity with the van der Waals and misfit energies derived from COSMO-RS. Although, and as expected, the enhanced 50 correlations with the experimental $\beta$ values were gathered with the COSMO-RS hydrogen-bonding energies and as shown hereinafter.

As previously mentioned, the solvatochromic parameters values determined by different authors are slightly different. In ${ }_{55}$ general, each group of researchers provide one relative polarity scale. Therefore, the $E_{\mathrm{HB}}$ values for each IL were correlated with the Kamlet-Taft $\beta$ parameters published by Welton and coworkers ${ }^{10}$ and Lungwitz et al. ${ }^{18}$. These literature sources ${ }^{10,18}$ were chosen since they represent the most complete databases found 60 for $\left[\mathrm{C}_{4} \mathrm{mim}\right]$-based ILs. These experimental values allow the inspection on the IL anion effect and the comparison between the hydrogen-bond basicity and the $E_{\mathrm{HB}}$. The $\beta$ experimental data ${ }^{10,18}$ and the respective COSMO-RS results are compiled in Table 2. The complete description of the IL anions is provided in Table 3.

65 Table 2. Hydrogen-bond basicity $(\beta)$ data, experimental ${ }^{1} \mathrm{H}$ NMR chemical shift of the $\mathrm{C} 2$-proton $(\delta / \mathrm{ppm})$ and hydrogen-bonding interaction energy in the equimolar cation-anion mixture $\left(E_{\mathrm{HB}} /\left(\mathrm{kJ} \cdot \mathrm{mol}^{-}\right.\right.$ $\left.{ }^{1}\right)$ ) taken from COSMO-RS calculations for $\left[\mathrm{C}_{4} \mathrm{mim}\right]$-based ILs.

\begin{tabular}{|c|c|c|c|c|}
\hline IL & $\beta^{10}$ & $\beta^{18}$ & $\delta^{*} / \mathrm{ppm}$ & $E_{\mathrm{HB}} /\left(\mathrm{kJ} \cdot \mathrm{mol}^{-1}\right)$ \\
\hline$\left[\mathrm{C}_{4} \mathrm{mim}\right]\left[\mathrm{N}\left(\mathrm{CF}_{3} \mathrm{SO}_{2}\right)_{2}\right]$ & 0.23 & 0.42 & 8.39049 & -9.86 \\
\hline$\left[\mathrm{C}_{4} \mathrm{mim}\right]\left[\mathrm{PF}_{6}\right]$ & 0.19 & 0.44 & 8.10815 & -2.88 \\
\hline$\left[\mathrm{C}_{4} \mathrm{mim}\right]\left[\mathrm{BF}_{4}\right]$ & 0.37 & 0.55 & 8.37390 & -9.79 \\
\hline$\left[\mathrm{C}_{4} \mathrm{mim}\right]\left[\mathrm{CF}_{3} \mathrm{SO}_{3}\right]$ & $0.48^{*}$ & 0.57 & 8.72675 & -17.11 \\
\hline$\left[\mathrm{C}_{4} \mathrm{mim}\right]\left[\mathrm{ClO}_{4}\right]$ & n.a. & 0.55 & n.a. & -13.11 \\
\hline$\left[\mathrm{C}_{4} \operatorname{mim}\right]\left[\mathrm{C}(\mathrm{CN})_{3}\right]$ & n.a. & 0.54 & 8.81457 & -16.73 \\
\hline$\left[\mathrm{C}_{4} \mathrm{mim}\right]\left[\mathrm{N}(\mathrm{CN})_{2}\right]$ & 0.60 & 0.64 & 8.99083 & -22.60 \\
\hline$\left[\mathrm{C}_{4} \mathrm{mim}\right][\mathrm{SCN}]$ & n.a. & 0.71 & 9.04029 & -17.01 \\
\hline$\left[\mathrm{C}_{4} \operatorname{mim}\right]\left[\mathrm{NO}_{3}\right]$ & n.a. & 0.74 & n.a. & -24.21 \\
\hline$\left[\mathrm{C}_{4} \operatorname{mim}\right]\left[\mathrm{CF}_{3} \mathrm{CO}_{2}\right]$ & $0.84^{*}$ & 0.74 & n.a. & -24.38 \\
\hline$\left[\mathrm{C}_{4} \mathrm{mim}\right] \mathrm{I}$ & n.a. & 0.75 & n.a. & -19.97 \\
\hline$\left[\mathrm{C}_{4} \mathrm{mim}\right]\left[\mathrm{CH}_{3} \mathrm{SO}_{4}\right]$ & 0.66 & 0.75 & n.a. & -21.88 \\
\hline$\left[\mathrm{C}_{4} \mathrm{mim}\right]\left[\mathrm{C}_{8} \mathrm{H}_{17} \mathrm{SO}_{4}\right]$ & $0.80^{*}$ & 0.77 & n.a. & -20.76 \\
\hline$\left[\mathrm{C}_{4} \mathrm{mim}\right]\left[\mathrm{CH}_{3} \mathrm{SO}_{3}\right]$ & 0.77 & 0.85 & n.a. & -29.03 \\
\hline$\left[\mathrm{C}_{4} \mathrm{mim}\right] \mathrm{Br}$ & n.a. & 0.87 & n.a. & -25.60 \\
\hline$\left[\mathrm{C}_{4} \mathrm{mim}\right] \mathrm{Cl}$ & 0.84 & 0.95 & n.a. & -30.72 \\
\hline$\left[\mathrm{C}_{4} \mathrm{mim}\right]\left[\left(\mathrm{CH}_{3} \mathrm{O}\right)_{2} \mathrm{PO}_{2}\right]$ & $1.12^{*}$ & 1.12 & 10.12070 & -32.85 \\
\hline$\left[\mathrm{C}_{4} \mathrm{mim}\right]\left[\mathrm{CH}_{3} \mathrm{CO}_{2}\right]$ & 0.85 & 1.20 & 10.58690 & -40.17 \\
\hline
\end{tabular}

*experimental data from this work

70

In general, the hydrogen-bond basicity values reported by Lungwitz et al. ${ }^{18}$ are higher than those published by Welton and co-workers ${ }^{10}$. These differences are a main result of the different solvatochromic dyes used by the two research groups. ${ }^{10,18}$

75 Anions such as acetate, dimethylphosphate and halogens present high hydrogen-bond basicities and thus an expected strong coordinating ability in aqueous solutions or in other media able to donate protons. At the other extreme of the ILs $\beta$ ranking, the fluorinated IL anions are found, such as $\left[\mathrm{N}\left(\mathrm{CF}_{3} \mathrm{SO}_{2}\right)_{2}\right]^{-},\left[\mathrm{PF}_{6}\right]^{-}$ $80,\left[\mathrm{BF}_{4}\right]^{-}$and $\left[\mathrm{CF}_{3} \mathrm{SO}_{3}\right]^{-}$. These IL anions are weak hydrogen bond acceptors, and when combined with the imidazolium cation, result in non-coordinating ILs. Structural changes to the IL anion, such as the introduction of electron withdrawing atoms or groups, also have a considerable influence on the hydrogen-bond basicity 85 values. For instance, considering the cyano-based ILs, [SCN]', $\left[\mathrm{N}(\mathrm{CN})_{2}\right]^{-}$and $\left[\mathrm{C}(\mathrm{CN})_{3}\right]^{-}$, there is a decrease in the IL anion's ability to accept hydrogen bonds with the increase number of $\mathrm{CN}$ groups attached to the central atom, despite the growing number of possible sites for interaction. The more $-\mathrm{CN}$ groups 90 are present, the smaller is the overall charge of the end group, and thus the electron density that is required for hydrogen-bonding. The introduction of fluorinated groups, from $\left[\mathrm{CH}_{3} \mathrm{CO}_{2}\right]^{-}$to $\left[\mathrm{CF}_{3} \mathrm{CO}_{2}\right]^{-}$and $\left[\mathrm{CH}_{3} \mathrm{SO}_{3}\right]^{-}$to $\left[\mathrm{CF}_{3} \mathrm{SO}_{3}\right]^{-}$, also leads to a decrease in the IL's hydrogen-bond basicity. The low polarizability of the 95 fluorinated groups and their electron withdrawing effect weakens the hydrogen-bonding ability with the hydrogen bond donor 
protons of the solvatochromic probe. Finally, there is an increase in the hydrogen-bond basicity with the increase of the alkyl side chain length attached to the IL anion, resulting from the electrondonating effect of the fatty groups $-c f$. data for methylsulphate5 and octylsulphate-based ILs. In summary, a large range of $\beta$ values are achievable by the structural modification of the IL anion. This pattern opens the door to the creation of ILs with defined hydrogen-bond basicity capable of reproducing the chemical behaviour of typical molecular solvents for specific 10 applications.

Fig. 1 depicts the correlation between the experimental $\beta$ parameter of each $\mathrm{IL}^{10,18}$ and the respective $E_{\mathrm{HB}}$ COSMO-RS values.
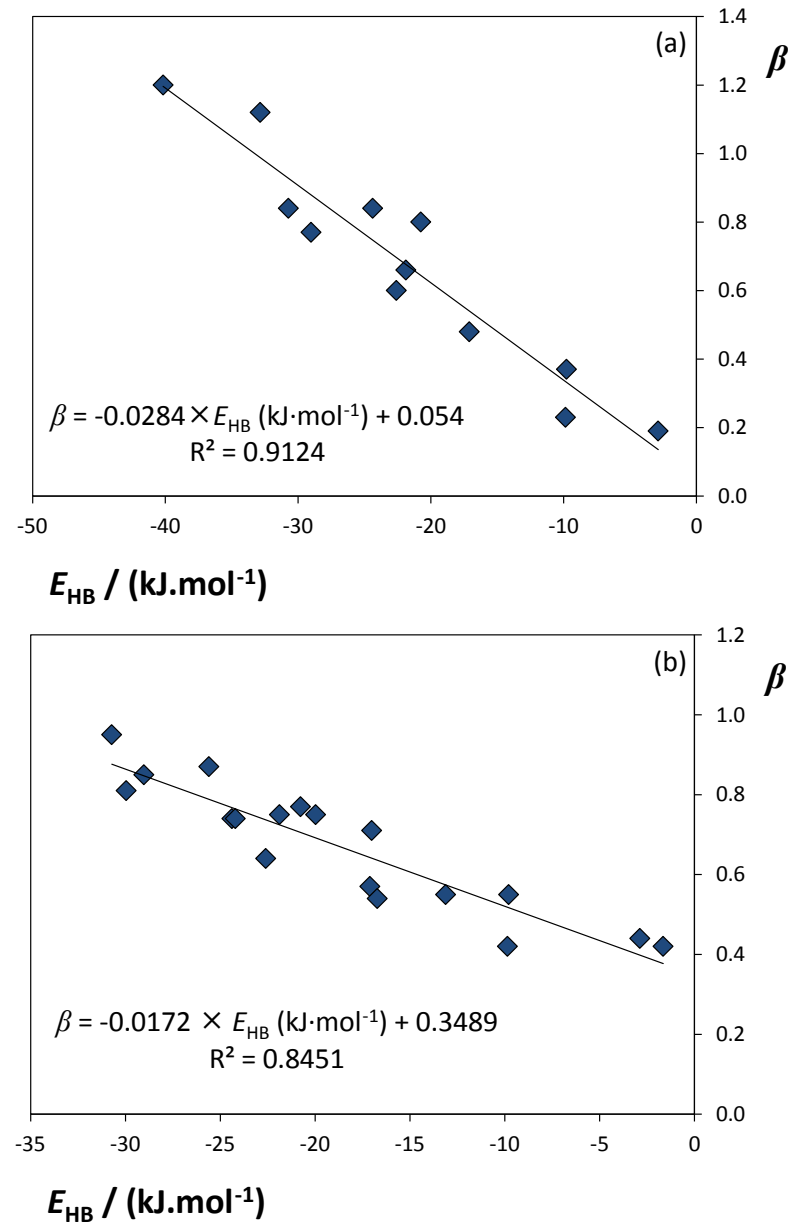

Fig. 1. Correlation between the experimental values of hydrogen-bond basicity $(\beta)$ and the $E_{\mathrm{HB}}$ predicted by COSMO-RS: (a) experimental data from Welton and co-workers ${ }^{10}$; (b) experimental data from Lungwitz et al. ${ }^{18}$.

50 At a first sight, it can be seen that there is a close relationship between the experimental hydrogen-bond basicity of $\left[\mathrm{C}_{4} \mathrm{mim}\right]-$ based ILs and the hydrogen-bonding energy of the pure cationanion pairs estimated by COSMO-RS. This correlation indicates that anions with an absolute lower hydrogen-bonding interaction 55 with the corresponding imidazolium cation are also those that are less able to accept hydrogen bonds when acting as the solvent environment. However, a closer look at Fig. 1 also points out to the existence of two different correlations for the experimental data taken from the two research groups. ${ }^{10,18}$ Higher correlation ${ }_{60}$ coefficients and a higher dependence on the $E_{\mathrm{HB}}$ values are observed with the experimental results from Welton and coworkers. ${ }^{10}$ This discrepancy can be ascribed to the different sets of dyes used by both groups and to the respective hydrogenbonding dependency of the IL anion with a given dye. ${ }^{10,18}$ ${ }_{65}$ However, both correlations depicted in Fig. 1 reveal a good agreement between the experimental hydrogen-bond basicity and the estimated hydrogen-bonding energies of the IL ions pairs. Based on this linear dependence and on the respective correlations it seems plausible to predict of the experimental $\beta$ 70 values.

Fig. 2 shows the relationship between the experimental and estimated $\beta$ parameters.
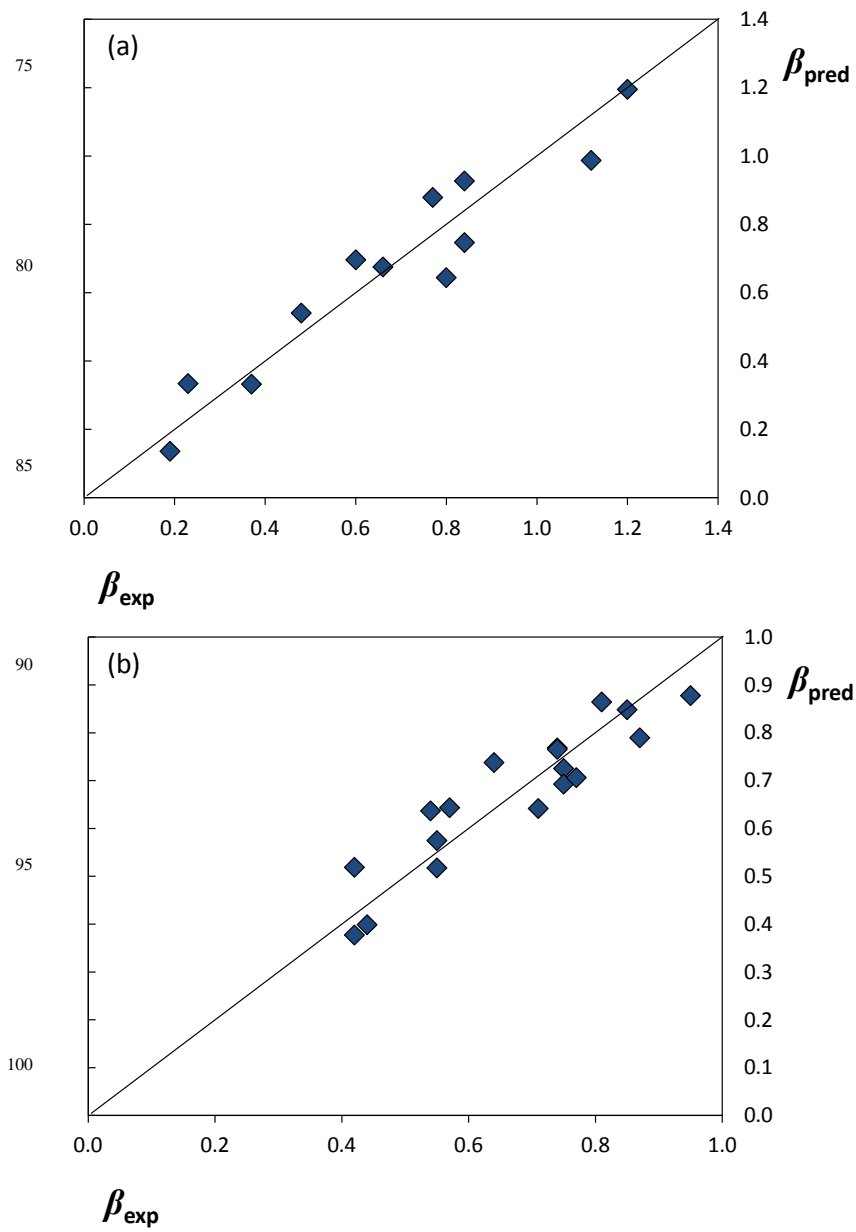

105

Fig. 2. Correlation between the predicted and experimental values of hydrogen-bond basicity ( $\beta_{\text {pred }}$ and $\beta_{\exp }$, respectively) based on the equations provided by the $E_{\mathrm{HB}}$ estimated by COSMO-RS: (a) experimental data from Welton and co-workers ${ }^{10}$; (b) experimental data 110 from Lungwitz et al. ${ }^{18}$.

In both examples displayed in Fig. 2 there is a close agreement between the predicted and experimental $\beta$ values meaning that the equations provided in Fig. 1 can be used to predict the hydrogenbond basicity of $\left[\mathrm{C}_{4} \mathrm{mim}\right]$-based ILs with reasonable accuracy.

115 Aiming at further evaluating the capability of COSMO-RS for the prediction of the IL anions to accept hydrogen bonds, 
additional ${ }^{1} \mathrm{H}$ NMR data were also determined in this work for pure ILs. The chemical shiftspresented here were measured for pure ILs, using an internal capillary containing the solvent and reference, to avoid the influences of solvent-IL interactions and 5 the concentration of the salt itself upon the chemical shifts. In this way, the chemical shifts of pure ILs represent the Differences in their ability to hydrogen-bond with the IL cation and as a function of the respective anion.

The correlation between the ${ }^{1} \mathrm{H}$ NMR chemical shift of the 10 proton in the C2-position of the imidazolium ring against the $E_{\mathrm{HB}}$ estimated by COSMO-RS is depicted in Fig. 3.
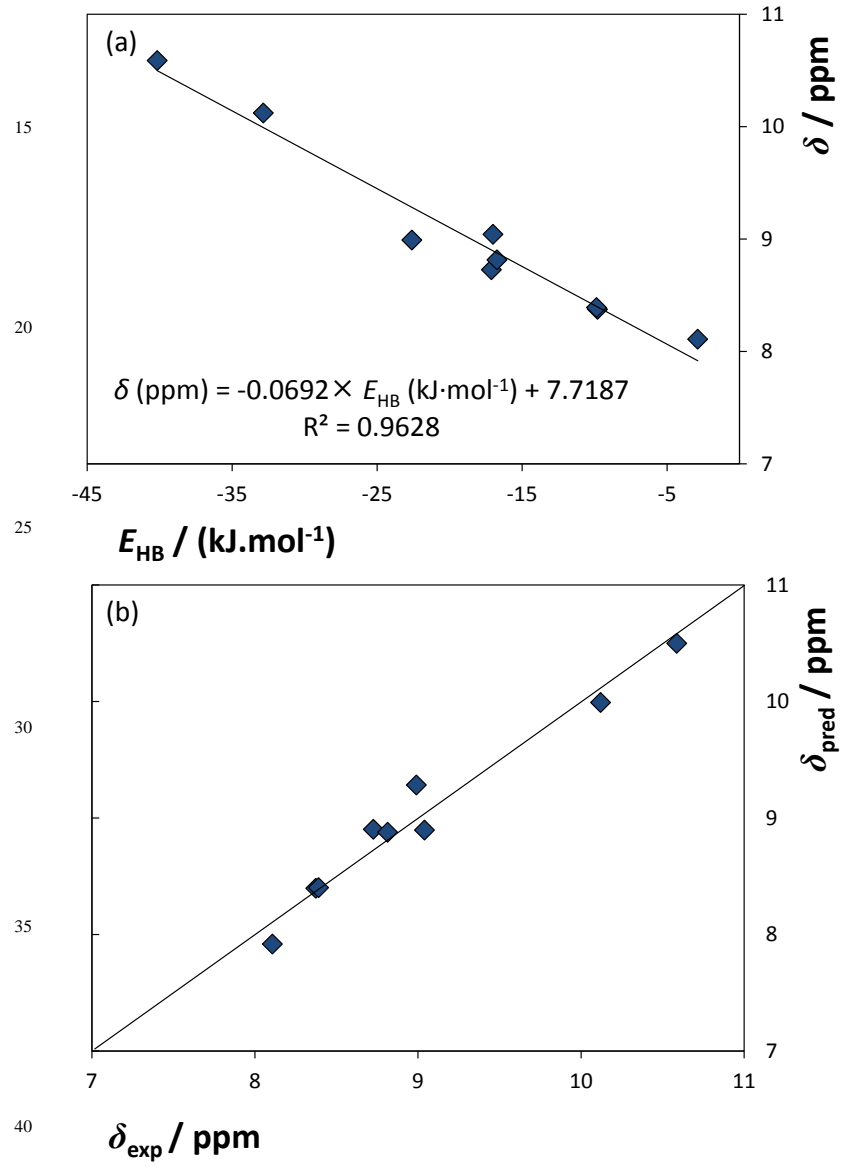

Fig. 3. (a) Correlation between the experimental values of ${ }^{1} \mathrm{H}$ NMR chemical shift of the C2-proton of the imidazolium ring and the $E_{\mathrm{HB}}$ estimated by COSMO-RS and (b) correlation between the predicted and 45 experimental values of the ${ }^{1} \mathrm{H}$ NMR chemical shift of the proton in the C2-position of the imidazolium ( $\delta_{\text {pred }}$ and $\delta_{\text {exp }}$, respectively).

The interaction of IL anions with $\left[\mathrm{C}_{4} \mathrm{mim}\right]^{+}$is complex in nature with preferential hydrogen-bonding with the most acidic hydrogen at the imidazolium cation, in the $\mathrm{C} 2$ position. Bonhôte 50 et al. ${ }^{25}$ demonstrated that the ${ }^{1} \mathrm{H}$ NMR chemical shift of the most acidic proton in 1,3-dialkylimidazolium moves to lower field with the increase of the anion basicity (in acetone solvent), and later on, Lungwitz and Spange ${ }^{18}$ revealed that the same chemical shift closely correlates with the hydrogen-bond basicity $(\beta)$ of ILs 55 with a common anion and can be used as a measure of its hydrogen-bonding strength. According to Fig. 3, there is a close relationship between the interaction strength of the IL anion with the imidazolium ring (represented by the ${ }^{1} \mathrm{H}$ NMR chemical shift) and $E_{\mathrm{HB}}$ estimated by COSMO-RS for a series of [ $\left.\mathrm{C}_{4} \mathrm{mim}\right]$-based ${ }_{60}$ compounds. The linear function depicted in Fig. 3 indicates that COSMO-RS is also able to predict the ${ }^{1} \mathrm{H}$ NMR chemical shift of the most acidic proton in the imidazolium ring as a result of the cation-anion hydrogen-bonding strength.

\section{Extended scale of the hydrogen-bond basicity of ILs}

65 Table 3. Hydrogen-bonding interaction energy in the equimolar cationanion mixture $\left(E_{\mathrm{HB}} /\left(\mathrm{kJ} \cdot \mathrm{mol}^{-1}\right)\right)$ taken from COSMO-RS calculations for $\left[\mathrm{C}_{4} \mathrm{mim}\right]$-based $\mathrm{ILs}$ as a new and extended scale of hydrogen-bond basicity. The anions list is presented in a decreasing order of hydrogenbond basicity of the IL anion.

\begin{tabular}{|c|c|c|}
\hline \multicolumn{3}{|c|}{$\left[\mathrm{C}_{4} \mathrm{mim}\right]$-based ILs } \\
\hline Anion & Abbreviation & $\begin{array}{c}\begin{array}{c}E_{\mathrm{HB}} / \\
\left(\mathrm{kJ} \cdot \mathrm{mol}^{-1}\right)\end{array} \\
\end{array}$ \\
\hline Acetate & {$\left[\mathrm{CH}_{3} \mathrm{CO}_{2}\right]^{-}$} & -40.17 \\
\hline Decanoate & {$\left[\mathrm{C}_{9} \mathrm{H}_{20} \mathrm{CO}_{2}\right]^{-}$} & -38.64 \\
\hline Bis(2,4,4-trimethylpentyl)phosphinate & {$\left[\mathrm{C}_{16} \mathrm{H}_{34} \mathrm{O}_{2} \mathrm{P}\right]^{-}$} & -38.45 \\
\hline Benzoate & {$\left[\left(\mathrm{C}_{6} \mathrm{H}_{5}\right) \mathrm{CO}_{2}\right]^{-}$} & -34.35 \\
\hline Diethylphosphate & {$\left[\left(\mathrm{C}_{2} \mathrm{H}_{5} \mathrm{O}\right)_{2} \mathrm{PO}_{2}\right]^{-}$} & -33.41 \\
\hline Dimethylphosphate & {$\left[\left(\mathrm{CH}_{3} \mathrm{O}\right)_{2} \mathrm{PO}_{2}\right]^{-}$} & -32.85 \\
\hline Dibutylphosphate & {$\left[\left(\mathrm{C}_{4} \mathrm{H}_{9} \mathrm{O}\right)_{2} \mathrm{PO}_{2}\right]^{-}$} & -32.46 \\
\hline Chloride & $\mathrm{Cl}^{-}$ & -30.72 \\
\hline Nitrite & {$\left[\mathrm{NO}_{2}\right]^{-}$} & -29.96 \\
\hline Methanesulfonate & {$\left[\mathrm{CH}_{3} \mathrm{SO}_{3}\right]^{-}$} & -29.03 \\
\hline Bromide & $\mathrm{Br}^{-}$ & -25.60 \\
\hline Salicylate & {$\left[\mathrm{C}_{7} \mathrm{H}_{5} \mathrm{O}_{3}\right]^{-}$} & -25.46 \\
\hline Toluene-4-sulfonate (tosylate) & {$\left[\mathrm{C}_{7} \mathrm{H}_{8} \mathrm{SO}_{3}\right]^{-}$} & -25.05 \\
\hline Trifluoroacetate & {$\left[\mathrm{CF}_{3} \mathrm{CO}_{2}\right]^{-}$} & -24.38 \\
\hline Nitrate & {$\left[\mathrm{NO}_{3}\right]^{-}$} & -24.21 \\
\hline Heptafluorobutanoate & {$\left[\mathrm{C}_{3} \mathrm{~F}_{7} \mathrm{CO}_{2}\right]^{-}$} & -22.64 \\
\hline Dicyanamide & {$\left[\mathrm{N}(\mathrm{CN})_{2}\right]^{-}$} & -22.60 \\
\hline 2-(2-methoxyethoxy)ethylsulphate & {$\left[\mathrm{C}_{5} \mathrm{OC}_{1} \mathrm{SO}_{4}\right]^{-}$} & -22.12 \\
\hline Ethylsulfate & {$\left[\mathrm{C}_{2} \mathrm{H}_{5} \mathrm{SO}_{4}\right]^{-}$} & -22.10 \\
\hline Methoxyethylsulphate & {$\left[\mathrm{C}_{3} \mathrm{H}_{7} \mathrm{OSO}_{4}\right]^{-}$} & -21.92 \\
\hline Methylsulphate & {$\left[\mathrm{CH}_{3} \mathrm{SO}_{4}\right]^{-}$} & -21.88 \\
\hline Ethoxyethylsulphate & {$\left[\mathrm{C}_{4} \mathrm{H}_{9} \mathrm{OSO}_{4}\right]^{-}$} & -21.78 \\
\hline Butylsulphate & {$\left[\mathrm{C}_{4} \mathrm{H}_{9} \mathrm{SO}_{4}\right]^{-}$} & -21.56 \\
\hline Octylsulphate & {$\left[\mathrm{C}_{8} \mathrm{H}_{17} \mathrm{SO}_{4}\right]^{-}$} & -20.76 \\
\hline Bis(malonato)borate & {$\left[\mathrm{C}_{6} \mathrm{H}_{4} \mathrm{BO}_{8}\right]^{-}$} & -20.33 \\
\hline Iodide & $\mathrm{I}^{-}$ & -19.97 \\
\hline Tri(fluoromethane)sulfonate & {$\left[\mathrm{CF}_{3} \mathrm{SO}_{3}\right]^{-}$} & -17.11 \\
\hline Bis(pentafluoroethyl)phosphinate & {$\left[\mathrm{PO}_{2}\left(\mathrm{C}_{2} \mathrm{~F}_{5}\right)_{2}\right]^{-}$} & -17.09 \\
\hline Thiocyanate & {$[\mathrm{SCN}]^{-}$} & -17.01 \\
\hline Tricyanomethane & {$\left[\mathrm{N}(\mathrm{CN})_{3}\right]^{-}$} & -16.73 \\
\hline Bis(salicylato)borate & {$\left[\mathrm{BC}_{14} \mathrm{H}_{8} \mathrm{O}_{6}\right]^{-}$} & -16.50 \\
\hline Bisbiphenyldiolatoborate & {$\left[\mathrm{BC}_{24} \mathrm{H}_{16} \mathrm{O}_{4}\right]^{-}$} & -14.42 \\
\hline Perclorate & {$\left[\mathrm{ClO}_{4}\right]^{-}$} & -13.11 \\
\hline Tetracyanoborate & {$\left[\mathrm{B}(\mathrm{CN})_{4}\right]^{-}$} & -12.48 \\
\hline Bis(trifluoromethylsulfonyl)methane & {$\left[\mathrm{CH}\left(\mathrm{CF}_{3} \mathrm{SO}_{2}\right)_{2}\right]^{-}$} & -11.16 \\
\hline Bis(oxalate)borate & {$\left[\mathrm{B}\left(\mathrm{C}_{2} \mathrm{O}_{4}\right)_{2}\right]^{-}$} & -10.88 \\
\hline Bis(trifluoromethanesulfonyl)imide & {$\left[\mathrm{N}\left(\mathrm{CF}_{3} \mathrm{SO}_{2}\right)_{2}\right]^{-}$} & -9.86 \\
\hline Tetrafluoroborate & {$\left[\mathrm{BF}_{4}\right]^{-}$} & -9.79 \\
\hline Bis(pentafluoroethylsulfonyl)imide & {$\left[\mathrm{N}\left(\mathrm{C}_{2} \mathrm{~F}_{5} \mathrm{SO}_{2}\right)_{2}\right]^{-}$} & -8.27 \\
\hline Tris(trifluoromethylsulfonyl)methide & {$\left[\mathrm{C}\left(\mathrm{SO}_{2} \mathrm{CF}_{3}\right)_{3}\right]^{-}$} & -7.20 \\
\hline Boron tetrachloride & {$\left[\mathrm{BCl}_{4}\right]^{-}$} & -4.13 \\
\hline Triiodide & {$\left[\mathrm{I}_{3}\right]^{-}$} & -2.99 \\
\hline Hexafluorophosphate & {$\left[\mathrm{PF}_{6}\right]^{-}$} & -2.88 \\
\hline Hexafluoroarsenate & {$\left[\mathrm{AsF}_{6}\right]^{-}$} & -1.72 \\
\hline Hexafluorostibate & {$\left[\mathrm{SbF}_{6}\right]^{-}$} & -1.65 \\
\hline Tetrachloroferrate & {$\left[\mathrm{FeCl}_{4}\right]^{-}$} & -0.99 \\
\hline Tris(pentafluoroethyl)trifluorophosphate & {$\left[\left(\mathrm{C}_{2} \mathrm{~F}_{5}\right)_{3} \mathrm{PF}_{3}\right]^{-}$} & -0.74 \\
\hline Bis(nonafluorobutyl)trifluorophosphate & {$\left[\left(\mathrm{C}_{4} \mathrm{~F}_{9}\right)_{2} \mathrm{PF}_{3}\right]^{-}$} & -0.69 \\
\hline
\end{tabular}

70

A single "polarity" parameter is not sufficient to explain all the variations in experimental results in solvent-mediated processes. Simple solvents, like $n$-alkanes, are limited in the number and type of interactions with the dissolved molecule. On the other 
hand, more complex solvents, with additional functional groups, are capable of having additional interactions, and ILs tend to fall within this category. Given their chemical structure and diversity of functional groups, ILs are able to establish dispersive, $\pi \cdots \pi$, $5 n \cdots \pi$, hydrogen-bonding and electrostatic interactions. The experimental polarity scales are a weighted average of solutesolvent interactions, and are thus more complex in nature for ILs. In this work we focused essentially on the hydrogen-bond basicity of ILs, which is strongly dominated by their anions, 10 while maintaining a fixed cation $\left(\left[\mathrm{C}_{4} \mathrm{mim}\right]^{+}\right)$. The $\beta$ value is a numerical description of the hydrogen-bond basicity of ILs and describes the importance of the individual ability of each IL anion to accept hydrogen bonds. Table 3 lists the COSMO-RS hydrogen-bonding interaction energies for an extended number of $15 \mathrm{IL}$ anions in a decreasing order of hydrogen-bond basicity.

The information provided in Table 3 henceforward can be used to understand the effect of different IL anions towards chemicalmediated processes. This extended polarity scale of the ability of the IL anion to hydrogen-bond can provide a priori information 20 to select an improved IL for a specific application before extensive and time-consuming experiments.

\section{Conclusions}

The great complexity of ILs to act either as hydrogen-bond donors or acceptors has resulted in great efforts in the literature 25 aimed at characterizing these fluids according to a polarity scale. Furthermore, this complexity, achieved by innumerable chemical structural variations, is valuable for the creation of "tailor-made" compounds. However, an efficient and realistic employment of ILs in scientific research, or even in industrial applications, 30 requires the accurate knowledge of their physical and chemical properties. One of the most important aspects of ILs when envisaging their use for replacing typical molecular solvents relies on the specific interactions occurring between the solvent and the dissolved solute. The reactivity of dissolved substrates, 35 reaction rates and reaction mechanisms are dependent on the solvent-solute interactions. The quantification of these solvent characteristics is thus an important tool to understand the physicochemical phenomena and chemical behaviour of systems involving ILs. For that purpose, several solvent parameters and 40 relative polarity scales for ILs have been proposed in the past few years. Nevertheless, these polarity scales are dependent on the set of solvatochromic dyes used, on the experimental procedure adopted and also on the purity of the ILs. Therefore, a proper comparison amongst different groups of research is not viable 45 and we are always limited to a relative polarity scale for a restricted number of ILs.

Aiming at overcoming the difficulties encountered with the establishment of a polarity scale for ILs, we proposed here the use of the hydrogen-bonding interaction energies, occurring in 50 the equimolar cation-anion mixtures $\left(E_{\mathrm{HB}} /\left(\mathrm{kJ} \cdot \mathrm{mol}^{-1}\right)\right)$, estimated from COSMO-RS calculations. Reasonable linear correlations between the experimental hydrogen-bond basicity values and the $E_{\mathrm{HB}}$ estimated from COSMO-RS were found, thus underlining the validity of the proposed methodology. Based on this dependence, 55 we provided an extended polarity scale capable of characterizing the IL anions' abilities to hydrogen-bond when acting as solvent media. The $E_{\mathrm{HB}}$ values estimated from COSMO-RS can be adequately used for routine screening, before extensive and timeconsuming experimental measurements by a trial and error 60 approach, and allow for the correct choice of an improved IL for a specific application.

\section{Experimental}

\section{Materials}

The ILs experimentally investigated were $\left[\mathrm{C}_{4} \mathrm{mim}\right]\left[\mathrm{CF}_{3} \mathrm{SO}_{3}\right]$ 65 (99 wt\% purity from Iolitec), $\left[\mathrm{C}_{4} \mathrm{mim}\right]\left[\mathrm{C}_{8} \mathrm{H}_{17} \mathrm{SO}_{4}\right]$ (97 wt\% purity form Merck), $\left[\mathrm{C}_{4} \mathrm{mim}\right]\left[\left(\mathrm{CH}_{3} \mathrm{O}\right)_{2} \mathrm{PO}_{2}\right]$ (98 wt\% purity from Iolitec) and $\left[\mathrm{C}_{4} \mathrm{mim}\right]\left[\mathrm{CF}_{3} \mathrm{CO}_{2}\right]$ (97 wt\% purity from Iolitec). All the ILs investigated are transparent, colourless and liquid at room temperature. The purity of each IL was also checked by ${ }^{1} \mathrm{H},{ }^{13} \mathrm{C}$, 70 and ${ }^{19} \mathrm{~F}$ (whenever applicable) NMR spectra and found to be in accordance with the purity levels given by the suppliers.

The dyes used were N,N-Diethyl-4-nitroaniline, $99 \%$ purity from Fluorochem, Reichardt dye, $90 \%$ purity from SigmaAldrich, and 4-nitroaniline, $99 \%$ purity from Aldrich.

75 The deuterium oxide used was acquired at Aldrich with > 99.96\% D atoms. The 3-(trimethylsilyl)propionic-2,2,3,3-d4 acid sodium salt (TSP) was from Aldrich with $>98 \%$ D atoms.

\section{Methods}

80 Solvatochromic assays. All the IL samples were dried under vacuum, at $50^{\circ} \mathrm{C}$ for $48 \mathrm{~h}$, before use. The dried $\mathrm{IL}(0.5 \mathrm{~mL})$ was taken and placed into an appropriate round-bottom flask and each dye was further added (Reichardt dye, $N, N$-diethyl-4-nitroaniline or 4-nitroaniline) in a dichloromethane solution. ${ }_{85}$ Dichloromethane was then removed under vacuum at $50^{\circ} \mathrm{C}$ (for 3 h). After cooling the UV-Vis spectra of all samples were recorded at $25{ }^{\circ} \mathrm{C}$ (thermostated sample holder) using a PC-controlled Perkin-Elmer Lambda 2 spectrophotometer. Further details on the experimental procedure can be found elsewhere. ${ }^{10}$

$90 \quad$ Nuclear magnetic resonance (NMR). The ${ }^{1} \mathrm{H}$ NMR spectra were obtained with pure IL samples (and after drying under vacuum) placed in NMR spectroscopy tubes containing sealed reference capillaries with $\mathrm{D}_{2} \mathrm{O}$ and TSP (3(trimethylsilyl)propionic-2,2,3,3-d4 acid sodium salt) as the 95 internal reference, and at $25{ }^{\circ} \mathrm{C}$. The ${ }^{1} \mathrm{H}$ NMR measurements were performed on a Bruker Avance 300 spectrometer operating at $300.13 \mathrm{MHz}$.

\section{COSMO-RS}

COSMO-RS ${ }^{20}$ is a thermodynamic model that combines quantum 100 chemistry, based on the dielectric continuum model known as COSMO (COnductor-like Screening MOdel for Real Solvents), with statistical thermodynamics calculations. COSMO calculations are performed in an ideal conductor, meaning that molecules are assumed as surrounded by a virtual conductor 105 environment, and the interactions are completely made on the conductor interface, taking into account the electrostatic screening and the back-polarization of the solute molecule. Therefore, COSMO gives a discrete surface around the solute molecule which is characterized by its geometry and screening 110 charge density $(\sigma)$ that iteratively corresponds to a minimum energetic state at the conductor. COSMO-RS treats the surface 
around the solute molecule as segments, and it also similarly treats the screening charge density of the respective segment, $\sigma$ '.

In the molecular interaction approach, the most significant molecular interaction energy modes are the electrostatic misfit 5 energy, and the hydrogen-bonding energy, $E_{\mathrm{HB}}$, defined according to the following equation,

$$
E_{\mathrm{HB}}=a_{\mathrm{eff}} \mathrm{c}_{\mathrm{HB}} \min \left(0 ; \min \left(0 ; \sigma_{\mathrm{donor}}+\sigma_{\mathrm{HB}}\right) \times \max \left(0 ; \sigma_{\text {acceptor }}-\sigma_{\mathrm{HB}}\right)\right)
$$

10 described as a function of the polarization charges of the two interacting segments, $\left(\sigma_{\text {acceptor }}, \sigma_{\text {donor }}\right)$ and where $a_{\text {eff }}$ is the effective contact area between two surface segments, $c_{\mathrm{HB}}$ is the hydrogen-bond strength and $\sigma_{\mathrm{HB}}$ is the threshold for hydrogenbonding. The van der Waals energy is also accounted but in an 15 approximate way; yet, it only depends on element specific van der Waals interaction parameters.

A number of conformations are available for the IL ions studied. In all the studied examples the lowest energy conformer was employed in the COSMO-RS calculations. Moreover, 20 independent files for the IL cation and anions were used. An equimolar cation-anion mixture was used to specifically determine the $E_{\mathrm{HB}}$ values of a pure IL. The quantum chemical COSMO calculation was performed in the Turbomole program package $^{26}$ with the BP density functional theory, giving the 25 surface charge density and the Ahlrichs-TZVP (triple- $\zeta$ valence polarized large basis set). ${ }^{26}$ The COSMOtherm program with the parameter file BP_TZVP_C2.1_1301 was used in all the calculations. ${ }^{26}$

\section{Notes and references}

$30{ }^{a}$ Departamento de Química, CICECO, Universidade de Aveiro, 3810-193 Aveiro, Portugal. Tel: +351 234370200; Fax: +351 234370084; E-mail address: maragfreire@ua.pt.

${ }^{b}$ Department of Chemistry, Imperial College London, South Kensington Campus, London, SW7 2AZ, UK.

35

${ }^{\S}$ Acronyms of the ILs experimentally investigated: 1-butyl-3methylimidazolium trifluoromethanesulfonate, $\left[\mathrm{C}_{4} \mathrm{mim}\right]\left[\mathrm{CF}_{3} \mathrm{SO}_{3}\right] ; 1-$ butyl-3-methylimidazolium octylsulphate, $\left[\mathrm{C}_{4} \mathrm{mim}\right]\left[\mathrm{C}_{8} \mathrm{H}_{17} \mathrm{SO}_{4}\right]$; 1-butyl3-methylimidazolium dimethylphosphate, $\left[\mathrm{C}_{4} \mathrm{mim}\right]\left[\left(\mathrm{CH}_{3} \mathrm{O}\right)_{2} \mathrm{PO}_{2}\right] ; 1$ 40 butyl-3-methylimidazolium trifluoroacetate, $\left[\mathrm{C}_{4} \mathrm{mim}\right]\left[\mathrm{CF}_{3} \mathrm{CO}_{2}\right]$.

This work was financed by national funding from FCTFundação para a Ciência e a Tecnologia, through projects PTDC/QUI-QUI/121520/2010 and PEst-C/CTM/LA0011/2013. 45 The authors also acknowledge FCT for the PhD grant SFRH/BD/74503/2010 of A.F.M. Cláudio.

\section{References}

1. (a) N. V. Plechkova and K. R. Seddon, Chem. Soc. Rev., 2008, 37, 123-150; (b) R. Renner, Environ. Sci. Technol., 2001, 35, 410A$50 \quad 413 \mathrm{~A}$

2. (a) J. Ranke, S. Stolte, R. Störmann, J. Arning and B. Jastorff, Chem. Rev. 2007, 107, 2183-2206; (b) D. Coleman and N. Gathergood, Chem. Soc. Rev. , 2010, 39, 600-637; (c) S. P. M. Ventura, A. M. M. Gonçalves, T. Sintra, J. L. Pereira, F. Gonçalves and J. A. P. Coutinho, Ecotoxicology, 2013, 22, 1-12.

3. (a) A. F. M. Cláudio, A. M. Ferreira, M. G. Freire and J. A .P. Coutinho, Green Chem., 2013, 15, 2002-2010; (b) J. F. B. Pereira, S. P. M. Ventura, F. A. Silva, S. Shahriari, M. G. Freire and J. A. P. Coutinho, Sep. Purif. Technol., 2013, 113, 83-89; (c) M. G. Freire, A.
60 R. R. Teles, R. A. S. Ferreira, L. D. Carlos, J. A. Lopes-da-Silva and J. A. P. Coutinho, Green Chem., 2011, 13, 3173-3180.

4. (a) P. Wasserscheid and T. Welton, Ionic Liquids in Synthesis, Wiley-VCH: New York, 2003; (b) T. Welton, Chem. Rev., 1999, 99, 2071-2084; (c) J. Dupont, R. F. de Souza and P. A. Suarez, Chem. Rev., 2002, 102, 3667-3692.

5. (a) S. S. Tan and D. R. MacFarlane, Top Curr. Chem., 2010, 290 311-339; (b) H. Wang, G. Gurau and R. D. Rogers, Chem. Soc. Rev., 2012, 41, 1519-1537; (c) L. C. Tomé, M. G. Freire, L. P. N. Rebelo, A. J. D. Silvestre, C. Pascoal Neto, I. M. Marrucho, C. S. Freire, Green Chem., 2011, 13, 2464-2470.

6. M. G. Freire, A. F. M. Cláudio, J. M. M. Araújo, J. A. P. Coutinho, I. M. Marrucho, J. N. Canongia Lopes and L. P. N. Rebelo, Chem. Soc. Rev., 2012, 41, 4966-4995; (b) M. D. Joshia and J. L. Anderson, RSC Adv., 2012, 2, 5470-5484; (c) L. Vidal, M. L. Riekkola and A. Canals, Anal. Chim. Acta, 2012, 715, 19-41.

7. (a) D. R. MacFarlane, J. M. Pringle, K. M. Jonansson, S. A. Forsyth and M. Forsyth, Chem. Commun. 2006, 1905-1917; (b) S. V. Dzyba and R. A. Bartsch, Tetrahedron Lett., 2002, 43, 4657-4659; (c) Y. Fukaya, A. Sugimoto and H. Ohno, Biomacromolecules, 2006, 7, 3295-3297; (d) R. M. Lau, M. J. Sorgedrager, G. Carrea, F. V. Rantwijk, F. Secundo and R. A. Sheldon, Green Chem., 2004, 6, 483487; (e) L. Crowhurst, R. Falcone, N. L. Lancaste, V. L. Mestre and T. Welton, J. Org. Chem., 2006, 71, 8847-8853; (f) L. Crowhurst, M. L. Lancaster, J. M. P. Arlandis and T. Welton, J. Am. Chem. Soc., 2004, 126, 11549-11555.

8. C. Reichardt, Green Chem., 2005, 7, 339-351.

9. (a) M. J. Kamlet and R. W. Taft, J. Am. Chem. Soc., 1976, 98, 377 383; (b) M. J. Kamlet and R. W. Taft, J. Am. Chem. Soc., 1976, 98 , 2886-2894; (c) M. J. Kamlet, J. L. Abboud and R. W. Taft, J. Am. $90 \quad$ Chem. Soc., 1977, 99, 6027-6038; (d) M. J. Kamlet, J. L. Abboud, M. H. Abraham and R. W. Taft, J. Org. Chem., 1983, 48, 2877-2887.

10. M. A. Ab Rani, A. Brant, L. Crowhurst, A. Dolan, M. Lui, N. H. Hassan, J. P. Hallett, P. A. Hunt, H. Niedermeyer, J. M. PerezArlandis, M. Schrems, T. Welton and R. Wilding, Phys. Chem. Chem,. Phys., 2011, 13, 16831-16840; (b) L. Crowhurst, P. R. Mawdsley, J. M. Perez-Arlandis, P. A. Salter, and T. Welton, Phys. Chem. Chem,. Phys., 2003, 5, 2790-2794.

11. (a) C. Chiappe and D. Pieraccini, J. Phys. Org. Chem., 2005, 18, 275 297; (b) C. Chiappe, C. S. Pomelli and S. Rajamani, J. Phys. Chem. B, 2011, 115, 9653-9661; (c) L. Crowhurst, P. R. Mawdsley, J. M. Perez-Arlandis, P. A. Salter, P. A. and T. Welton, Phys. Chem. Chem. Phys., 2003, 5, 2790-2794; (d) T. V. Doherty, M. Mora-Pale, S. E. Foley, R. J. Linhardt and J. S. Dordick, Green Chem., 2010, 12 , 1967-1975; (e) R. Lungwitz, V. Strehmel and S. Spange, New J. Chem., 2010, 34, 1135-1140.

12. (a) Y. Marcus, Chem. Soc. Rev., 1993, 22, 409-416; (b) S. Spange, E. Vilsmeier, K. Fischer, A. Reuter, S. Prause, Y. Zimmermann Ch. Schmidt, Macromol. Rapid Commun., 2000, 21, 643-659.

13. (a) S. N. Baker, G. A. Baker and F. V. Bright, Green Chem., 2002, 4, 165-169; (b) B. R. Mellein, S. N. V. K. Aki, R. L. Ladewski and J. F. Brennecke, J. Phys. Chem. B, 2007, 111, 131-138; (c) S. Trivedi, N. I. Malek, K. Behera and S. Pandey, J. Phys. Chem. B, 2010, 114, 8118-8125.

14. P. Wasserschied and T. Welton, Ionic Liquids in Synthesis, VCH Wiley, Weinheim, 2007.

15. P. G. Jessop, D. A. Jessop, D. Fu and P. Lam, Green Chem., 2012, 14, 1245-1259.

16. C. Chiappe and D. Pieraccini, J. Phys. Chem. A, 2006, 110, $4937-$ 4941.

120 17. Y. Wu, T. Sasaki, K. Kazushi, T. Seo and K. Sakurai, J. Phys. Chem. $B, 2008,112,7530-7536$.

18. (a) R. Lungwitz, M. Friedrich, W. Linert and S. Spange, New J. Chem., 2008, 32, 1493-1499; (b) R. Lungwitz and S. Spange, New J. Chem., 2008, 32, 392-394; (c) R. Lungwitz, V. Strehmel and S. Spange, New J. Chem., 2010, 34, 1135-1140.

19. H. Niedermeyer, C. Ashworth, A. Brandt, T. Welton and P. A. Hunt, Phys. Chem. Chem. Phys., 2013, 15, 11566-11578.

20. (a) A. Klamt, J. Phys. Chem., 1995, 99, 2224-2235; (b) A. Klamt, COSMO-RS from quantum chemistry to fluid phase thermodynamics and drug design, Elsevier, Amsterdam, Boston, 2005; (c) A. Klamt, 
F. Eckert, Fluid Phase Equilibr., 2000, 172, 43-72; (d) A. Klamt and G. Schuurmann, J. Chem. Soc., Perkin Trans. 2, 1993, 799-805.

21. (a) M. G. Freire, S. P. M. Ventura, L. M. N. B. F. Santos, I. M. Marrucho and J. A. P. Coutinho, Fluid Phase Equilibr., 2008, 268, 74-84; (b) M. G. Freire, L. M. N. B. F. Santos, I. M. Marrucho and J. A. P. Coutinho, Fluid Phase Equilibr., 2007, 255, 167-178; (c) A. R. Ferreira, M. G. Freire, J. C. Ribeiro, F. M. Lopes, J. G. Crespo and J. A. P. Coutinho, Ind. Eng. Chem. Res., 2011, 50, 5279-5294; (d) A. R. Ferreira, M. G. Freire, J. C. Ribeiro, F. M. Lopes, J. G. Crespo and J.

10 A. P. Coutinho, Ind. Eng. Chem. Res., 2012, 51, 3483-3507.

22. (a) K. A. Kurnia and J. A. P. Coutinho, Ind. Eng. Chem. Res., 2013, 52, 13862-13874; (b) J. Palomar, M. Gonzalez-Miquel, A. Polo and F. Rodriguez, Ind. Eng. Chem. Res., 2011, 50, 3452-3463; (c) M. Gonzalez-Miquel, J. Palomar and F. Rodriguez, J. Phys. Chem. B, 2013, 117, 296-306.

23. (a) M. G. Freire, L. M. N. B. F. Santos, A. M. Fernandes, J. A. P. Coutinho and I. M. Marrucho, Fluid Phase Equilib., 2007, 261, 449454; (b) A. F. M. Cláudio, C. F. C. Marques, I. Boal-Palheiros, M. G. Freire and J. A. P. Coutinho, Green. Chem., 2013,

20 DOI:10.1039/C3GC41999A; (c) A. F. M. Cláudio, A. M. Ferreira, M. G. Freire and J. A. P. Coutinho, Green Chem., 2013, 15, 20022010; (d) A. George, K. Tran, T. J. Morgan, P. I. Benke, C. Berrueco, E. Lorente, B. C. Wu, J. D. Keasling, B. A. Simmons and B. M. Holmes, Green Chem., 2011,13, 3375-3385.

25 24. (a) T. P. Wells, J. P. Hallet, C. K. Williams, T. Welton, J. Org. Chem., 2008, 73, 5585-5588; (b) A. F. M. Cláudio, A. M. Ferreira, S. Shahriari, M. G. Freire and J. A. P. Coutinho, J. Phys. Chem. B, 2011, 115, 11145-11153; (c) Y. Fukayaa, K. Hayashia, M. Wadab and H. Ohno, Green Chem., 2008, 10, 44-46.

30 25. P. Bonhôte, A. -P. Dias, N. Papagergiou, K. Kalyanasundaram and M. Grätzel, Inorg. Chem., 1996, 35, 1168-1178.

26. (a) A. Schäfer, A. Klamt, D. Sattel, J. C. W. Lohrenz and F. Eckert, Phys. Chem. Chem. Phys., 2000, 2, 2187-2193; (b) A. Schäfer, C. Huber and R. Ahlrichs, J. Chem. Phys., 1994, 100, 5829-5835; (c) A.

35 Klamt and F. Eckert, COSMOtherm program (Version C3.0 Release 13.01), 2013, COSMOlogic GmbH \& Co. KG: Leverkusen, Germany. 